\title{
Study and Optimisation of Supply Duct Bend and Diffuser in HVAC System for a Classroom
}

\author{
Shivam Agarwal \\ U.G, B.tech Student, Dept. of Mechanical engineering \\ SRM IST NCR Campus \\ Modinagar, U.P, India
}

\begin{abstract}
This paper presents numerical predictions and results of air flow and pressure distribution in common possible iterations of duct and diffuser having: 1. square, rectangle and circular duct shape, 2. square duct with side 12in, $15 \mathrm{in}$ and $18 \mathrm{in}$ and 3 . bend radius to width ratio of $0,0.5,1$ and 2 . The system is designed to develop an optimal system to reduce the noise levels in a classroom which are far above the recommended value of 35dB by WHO in an engineering institution designed according to the Common Public Works Department(CPWD) norms while also bridging the gap between the industry and the consumer.
\end{abstract}

The iterations were designed on fusion 360 and tetrahedron meshing was done in ANSYS after defining the boundaries of geometry of CAD design. The inlet velocities varied as per the different diffuser size, shape and angles. The inlet velocity lies in the range of $1.5 \mathrm{~m} / \mathrm{s}$ to $3 \mathrm{~m} / \mathrm{s}$.

After setting up the solver and choosing k-omega SST model for solving, calculation was performed for 3000 iterations using hybrid initialization to reduce the residuals as much as possible for the results to converge for accurate results. Material properties of aluminum and properties of the fluid were set.

Among different groups, results based on different shapes showed that circular duct displayed gradual pressure and velocity drop at the lower bend of the wall than in the case of rectangle or square. While, in case of duct with different sizes, as size of duct increased, frictional losses increased, while pressure drop, noise levels and eddy current formation significantly reduced. In case of different bend radius to width ratio(r/W), as r/W increased, eddy formation and boundary layer separation, pressure drop, turbulence and noise levels decreased.

Therefore, the study showed that a circular duct, with a diameter of $15 \mathrm{in}$ having r/W ratio of 2 would significantly reduce the sound levels and be the optimum solution for the classroom and adding 2-3 vanes would further improve the performance of the system and maximize the required effort.

Keywords:- HVAC; Ansys; CFD; Duct; Diffuser; Pressure drop.

\author{
Danishq Gera \\ U.G, B.tech Student, Dept. of Mechanical engineering \\ SRM IST NCR Campus \\ Modinagar, U.P, India
}

\section{INTRODUCTION}

Heating, ventilation, and air conditioning (HVAC) system is advancement to indoor environmental comfort. Its aim is to provide thermal comfort with suitable air quality index (AQI). HVAC design is a regulation under mechanical engineering, based on heat transfer, fluid mechanics and thermodynamics.

An educational institution in India has numerous noise adding equipments and a HVAC system is the major contributor to it. It results in higher noise levels in classrooms of up to $80 \mathrm{~dB}$, which is far above the WHO recommended level of $35 \mathrm{~dB}$. Excessive noise leads to stress, productivity and concentration losses, communication difficulties and fatigue. It also leads to hearing losses, cardiovascular diseases and tinnitus. The basic requirements needed of the HVAC system is of thermal comfort, efficiency and space utilization and are often compromised and not taken into account all together.

Previous works in the field present CFD predictions and comparisons for pressure drop effect in 90 degree elbow which have been conducted by Moujaes in 2009 presents new results for numerical predictions of air flow and pressure distribution in two commonly used elbows: $1.90^{\circ}$ mitered duct elbows with turning vanes having $0.05 \mathrm{~m}$ radius, $0.038 \mathrm{~m}$ vane spacing and $2.90^{\circ}$ mitered duct elbows without turning vanes, in $0.2 \times 0.2 \mathrm{~m}$ and $8 \times 8$ in. duct cross section using the STAR-CD computational fluid dynamics(CFD) code. In 2003, Ramada, Pasha and Mugabe performed CFD simulation for prediction of swirl effect in diffusion duct. The study involved the CFD analysis for the prediction of swirl effect on the characteristics of a steady, incompressible flow through an S-shaped diffusing duct by keeping swirl angle of $10^{\circ}$. The design of HVAC duct and diffuser system commonly evaluated frictional losses to determine the major and dynamic losses for the elements, but here, a numerical model is designed in compliance to the government guidelines and noise levels recommendations by WHO have been taken into account. The procedure and methodology involved was in bifurcation of both customer experience and industry standards. Various factors like shape, size of the duct bend radius at the elbows have been taken into account while designing the system and CFD was performed on various iterations to analyse for pressure and energy balancing in the system. 
This survey of previously done works on heating, ventilation and air conditioning system shows that a comprehensive study focused around development of optimal system to minimize impact on student perception and looking after tutor's vocal hygiene whilst consumers can choose the system on the basis of their requirements is a vital addition to the literature of the field. The importance of the work is such that it bridges the gap between the customer and industry and provide with the most optimal solution according to the needs.

\section{MODEL PARAMETERS}

To analyse the various performance factors in a duct and diffuser of an HVAC system, we began by selecting a room complaint to the government norms for classroom in an engineering and technology institution. A carpet area of 33.5 meter square was selected accommodating a maximum of 20 students. After taking into consideration necessary board dimensions, room for projecting and for a comfortable line-of-sight for the students a ceiling height of 10 feet was decided complying with the government norms.

Keeping thermal comfort as the underlying theme, air change rate $(\mathrm{ACH})$ which is the quantity of air to be added or removed to the selected room per unit volume of space is selected as 10 .
Calculation of flow of air is calculated keeping in mind that the floor is neither too less or too high. The calculated CFM (cubic feet per minute) by the data provided by ASHRAE handbook came out to be 602 .

Sheet metal aluminum with the roughness factor of 0.0001 feet was selected based on the usage, availability and least roughness factor so as to account for least pressure losses. While diffuser of various shapes like square rectangle and circle were selected from the manufacturer's data based on the calculated CFM, noise criteria and throw required.

\section{CAD MODELS}

The diffuser is placed in the center of the ceiling so that air could be thrown by the diffuser at equal distance, hence there is equal cooling of the room. Keeping in mind the approach of negative space the software ANSYS uses for computational flow, diffusers were designed and modeled to have negative volume representing volume of the fluid. Based on the above assertions, 8 iterations were modeled varying in shape, size and bend radius in Fusion360.

\begin{tabular}{|c|c|c|c|c|c|c|}
\hline Iteration & $\begin{array}{l}\text { Width } \\
\text { (In) }\end{array}$ & $\begin{array}{l}\text { Breadth } \\
\quad \text { (In) }\end{array}$ & $\begin{array}{l}\text { Duct Length } \\
\text { (In) }\end{array}$ & $\begin{array}{c}\text { Duct Height } \\
\text { (In) }\end{array}$ & $\begin{array}{l}\text { Bend Radius } \\
\text { (In) }\end{array}$ & Cross section \\
\hline \multicolumn{7}{|c|}{ Based on Size } \\
\hline S12 & 12 & 12 & 12 & 12 & 12 & Square \\
\hline S15 & 15 & 15 & 15 & 15 & 15 & Square \\
\hline S18 & 18 & 18 & 18 & 18 & 18 & Square \\
\hline \multicolumn{7}{|c|}{ Based on Shape } \\
\hline R1512 & 15 & 12 & 15 & 15 & 15 & Rectangle \\
\hline $\mathrm{C} 16$ & $16 \varnothing$ & - & 16 & 16 & 16 & Circle \\
\hline \multicolumn{7}{|c|}{ Based on $r / W$} \\
\hline R0 & 15 & 15 & 15 & 15 & 0 & Square \\
\hline $\mathrm{R} 0.5$ & 15 & 15 & 15 & 15 & 7.5 & Square \\
\hline $\mathrm{R} 1$ & 15 & 15 & 15 & 15 & 15 & Square \\
\hline $\mathrm{R} 2$ & 15 & 15 & 15 & 15 & 30 & Square \\
\hline
\end{tabular}

Table 1:- Design iterations 


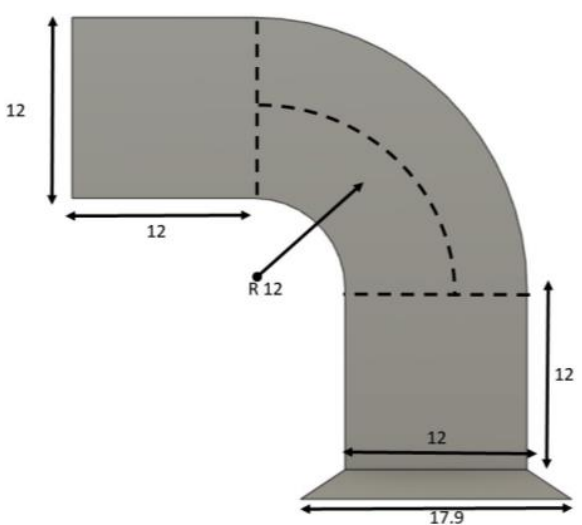

Fig. 1. S12 design

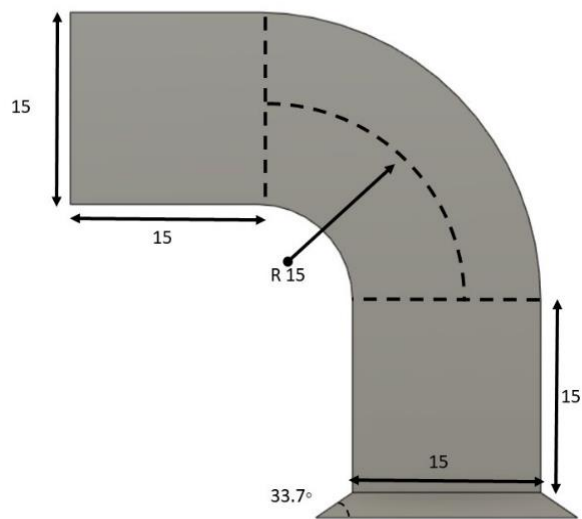

Fig. 2. S15 design

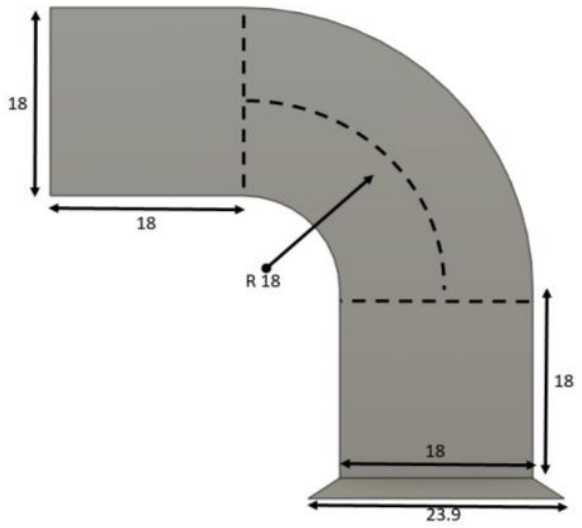

Fig. 3. S18 design

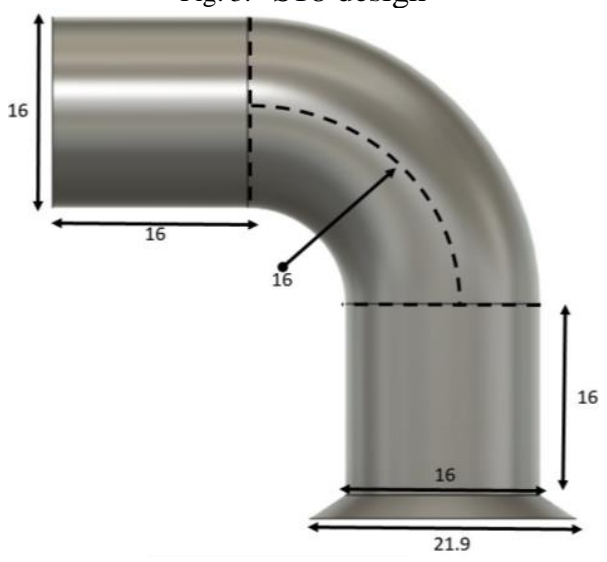

Fig. 4. C16 design

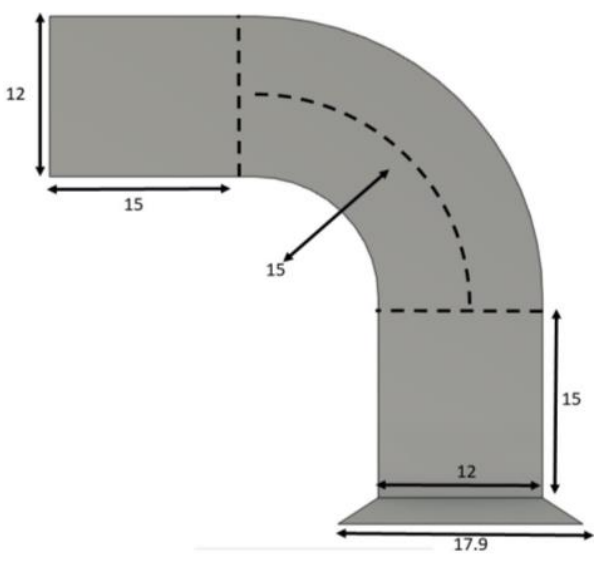

Fig. 5. R1512 design

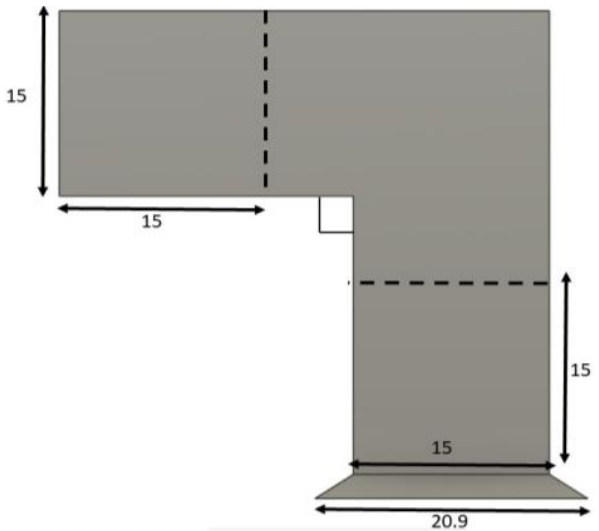

Fig. 6. R0 design

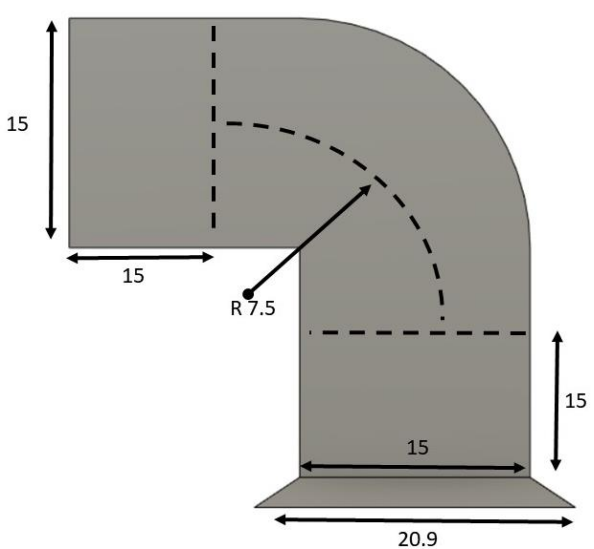

Fig. 7. R0.5 design

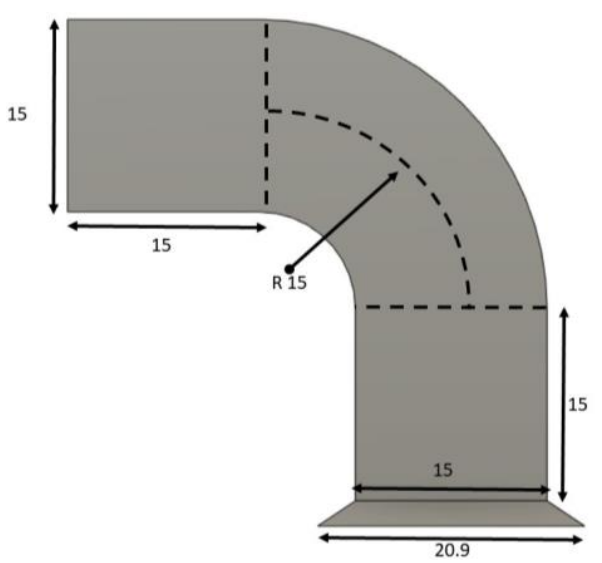




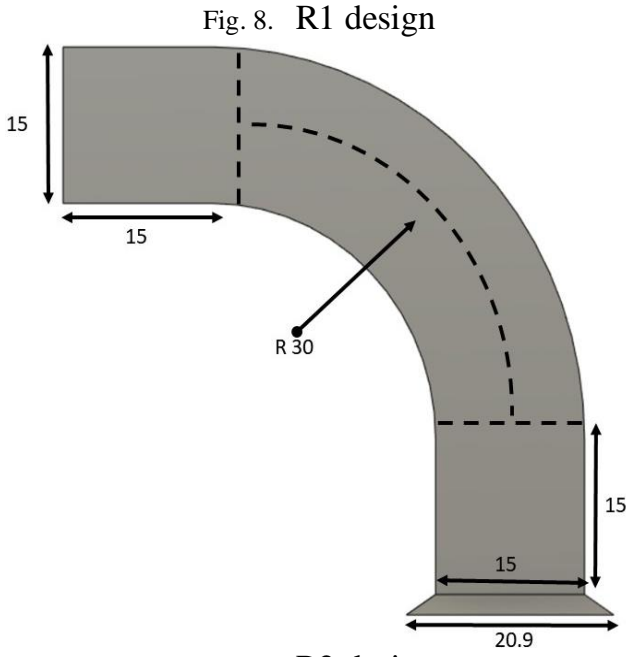

Fig. 9. R2 design

\section{MESHING}

To obtain a precise and accurate results of the CFD simulation, each iteration was meshed with a different base size based on the different conditions like size, shape and bend radius.

While meshing, mesh type, meshing method, size function and relevance factor were kept constant to tetrahedron, patch confirming, curvature and fine respectively to obtain 150000-200000 elements in each mesh.

\section{PHYSICAL AND BOUNDARY CONDITIONS}

\begin{tabular}{|c|c|c|}
\hline Properties & Model & Justification \\
\hline Space & $3-\mathrm{D}$ & $\begin{array}{r}\text { Meshes are } 3 \\
\text { dimensional }\end{array}$ \\
\hline Motion & Stationary & Zone is stationary \\
\hline Time & Steady & $\begin{array}{l}\text { Iterations are required to } \\
\text { reduce the residual errors } \\
\text { and to get converged } \\
\text { solutions }\end{array}$ \\
\hline Material & Air & $\begin{array}{l}\text { Working fluid inside the } \\
\text { room is air }\end{array}$ \\
\hline Flow & Segregated & $\begin{array}{l}\text { Stratified, wavy and } \\
\text { annular flow of air }\end{array}$ \\
\hline Density & $\begin{array}{l}\text { Constant } \\
\text { density }\end{array}$ & $\begin{array}{c}\text { Density is invariant } \\
\text { throughout the } \\
\text { continuum }\end{array}$ \\
\hline $\begin{array}{l}\text { Viscous } \\
\text { Regime }\end{array}$ & Turbulent & $\begin{array}{c}\text { Flow of air with } \\
\text { amplifications of } \\
\text { infinitesimal disturbances }\end{array}$ \\
\hline $\begin{array}{l}\text { Turbulent } \\
\text { Models }\end{array}$ & $\begin{array}{l}\text { K-omega } \\
\text { turbulence } \\
\text { model }\end{array}$ & Predicts well near wall \\
\hline Wall Surface & Smooth flow & Smooth scalar view \\
\hline
\end{tabular}

Table 2:- Physical Conditoins

\begin{tabular}{|c|c|}
\hline \multicolumn{2}{|c|}{ INLET BOUNDARY CONDITIONS } \\
\hline Type & Velocity inlet \\
\hline Velocity & $1.5-3.0 \mathrm{~m} / \mathrm{s}$ \\
\hline Turbulent Intensity & $5 \%$ \\
\hline Turbulent Viscocity Ration & 10 \\
\hline OUTLET BOUNDARY CONDITIONS \\
\hline Type & Outlet vent \\
\hline Gauge Pressure & 0 Pa \\
\hline Turbulent Intensity & $5 \%$ \\
\hline Turbulent Viscocity Ration & 10 \\
\hline
\end{tabular}

Table 3:- Boundary Conditions

\section{CFD ANALYSIS}

Using ANSYS fluent, the main aim here is to reduce the noise so that the audio quality delivered to the students is least hindered by the HVAC system and for the efficient classroom sessions to be taken place in the institution. To have less disturbances due to noise and vibration, the velocity of air flow should be kept low and activity at diffuser have been noticed to analyse the effect of condo effect and for swift movement of air through the surface of ceiling to the maximum possible distance. $\mathrm{r} / \mathrm{W}$ ratio has been varied from 0 to 2 to notice the frictional losses due to change in this ratio. For R1 iteration, data from S15 is taken. Size and shape has been varied on the basis of manufacturers data provided in catalogues.

\section{RESULTS}

A. On the basis of size

$>$ While performing CFD on iterations varying in sizes, the maximum pressure was observed at the upper wall of bend in all designs while lower wall of the bend noted the minimum.

$>$ Due to higher inlet velocity, range of the pressure is maximum in $12 \times 12$ and also significant pressure drop at the bend. Therefore, observing the maximum pressure drop.

$>$ As the size increases, the resistance in flow and travel time inside the duct increased due to larger size.

$>$ The smaller cross sectional areas proved efficient in gaining velocity throughout the bend.

$>$ As the size of the duct increases, the frequency of eddy current formation subsequently decreased.

$>$ The region devoid of downstream flow after the bend is similar in all designs due operation at optimal conditions. 


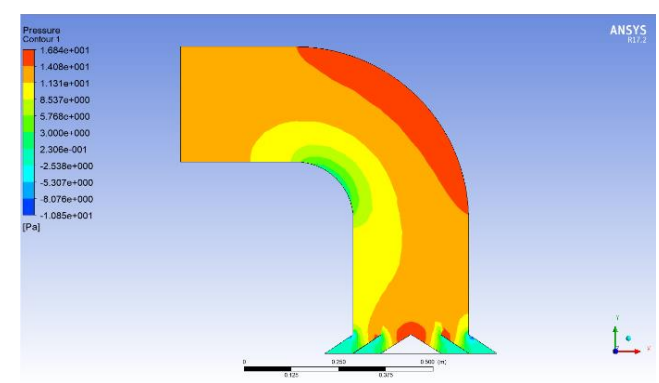

Fig. 10. Pressure contour S12

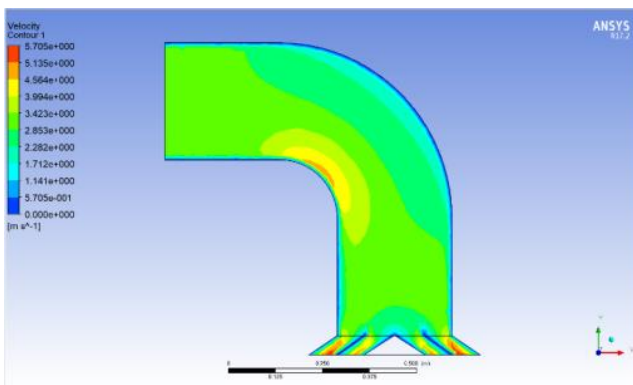

Fig. 11. Velocity contour S12

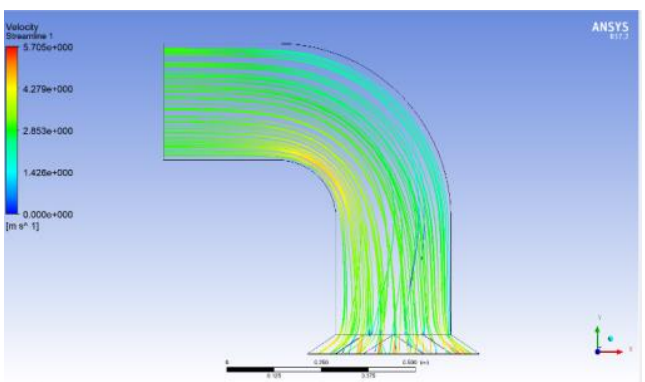

Fig. 12. Velocity streamline S12

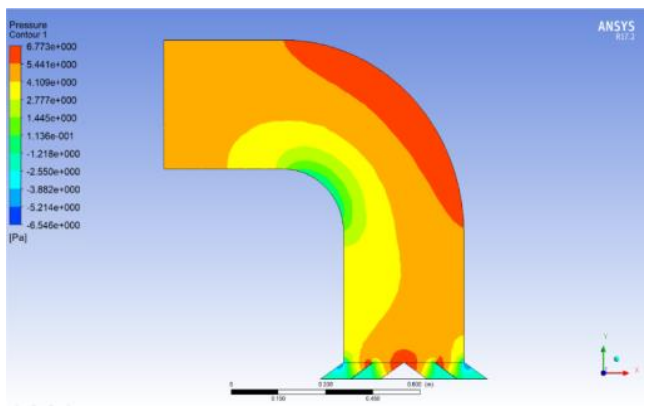

Fig. 13. Pressure contour S15

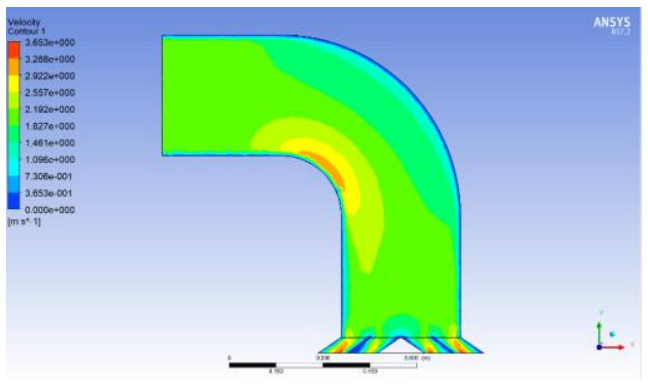

Fig. 14. Velocity contour S15

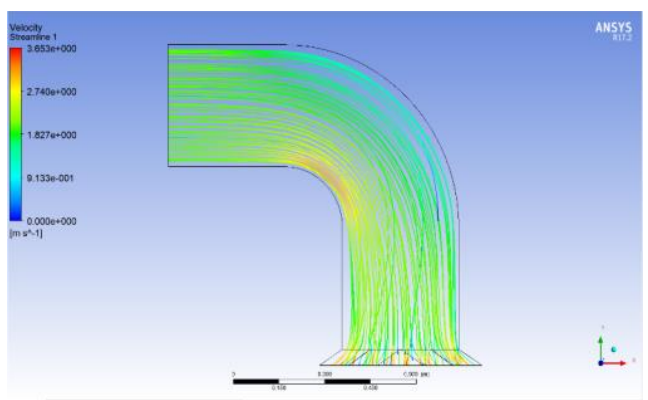

Fig. 15. Velocity streamline S15

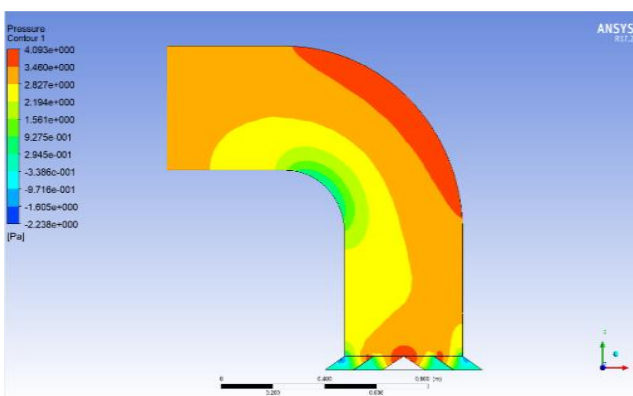

Fig. 16. Pressure contour S18

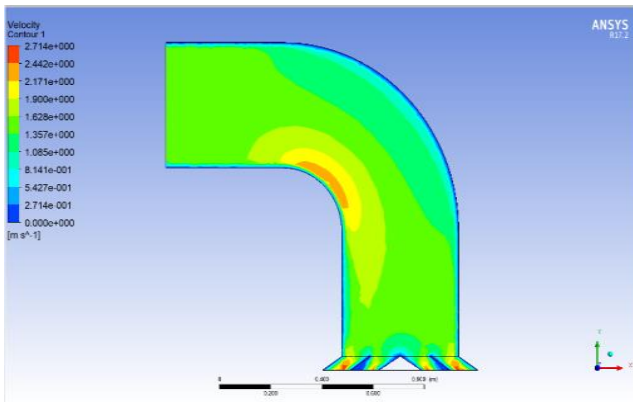

Fig. 17. Velocity contour S18

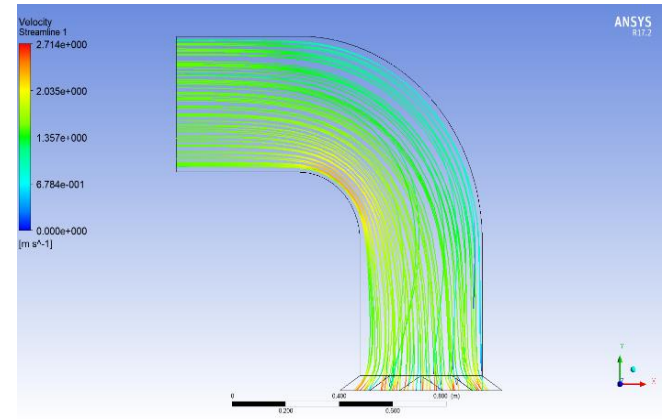

Fig. 18. Velocity streamline S18

\begin{tabular}{|c|c|c|c|}
\hline & S12 & S15 & S18 \\
\hline Max Pressure[Pa] & 16.844 & 6.773 & 4.093 \\
\hline Min Pressure[Pa] & -10.845 & -6.545 & -2.238 \\
\hline Inlet Pressure[Pa] & 12.203 & 5.237 & 2.937 \\
\hline Bend Pressure[Pa] & 10.517 & 4.862 & 2.505 \\
\hline Outlet Pressure[Pa] & 8.131 & 3.051 & 1.909 \\
\hline Inlet Velocity[m/s] & 3 & 2 & 1.5 \\
\hline Outlet Velocity[m/s] & 4.43 & 2.9 & 2.24 \\
\hline Pressure Drop[Pa] & 4.072 & 2.186 & 1.028 \\
\hline
\end{tabular}


Table 4:- Results on the Basis of Size

B. On the basis of shape

$>$ CFD simulations on different shaped duct with an equivalent diameter revealed that due to larger cross section area than the counterparts, circular type has the lowest inlet pressure.

$>$ The flow of air is found to be streamlined and more composed in circular than its counterparts.

$>$ Better pressure contours are noticed in circular diffuser on the account of gradual increment of pressure as the air passes through the diffuser.

$>$ Due to natural symmetry in circular duct, pressure drop is gradual and even at the bends than in the case of square or rectangle type.

Velocity gain across the duct is lower in circular duct as velocity drop at the lower wall of the bend is lower than in rectangular or square shaped.

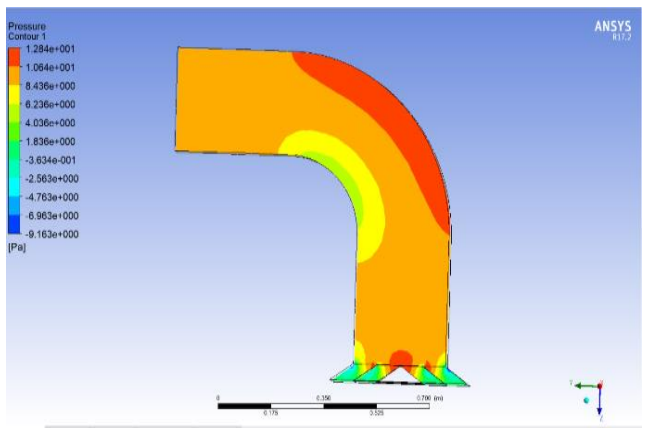

Fig. 19. Pressure contour R1512

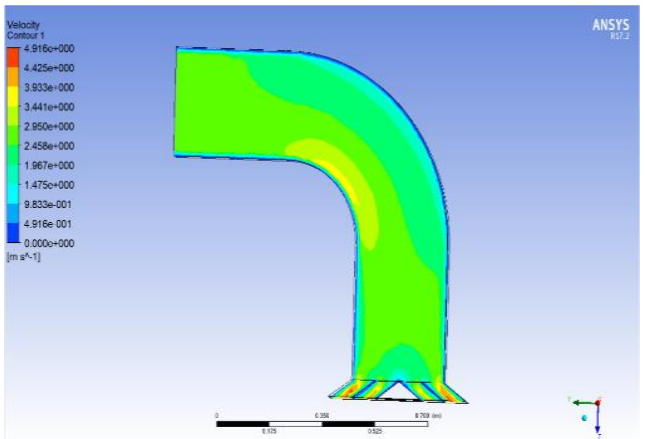

Fig. 20. Velocity contour R1512

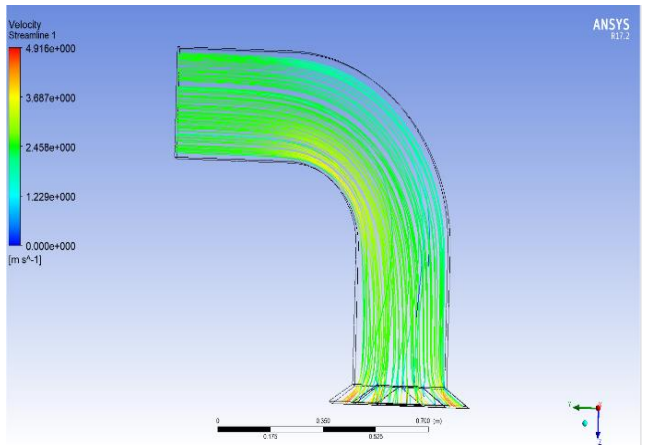

Fig. 21. Velocity streamline R1512

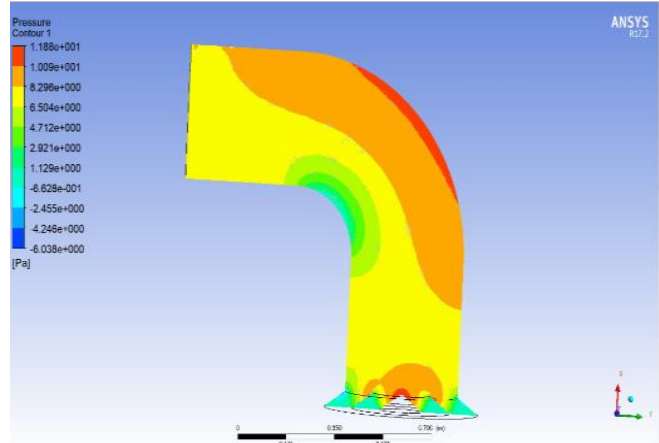

Fig. 22. Pressure contour C16

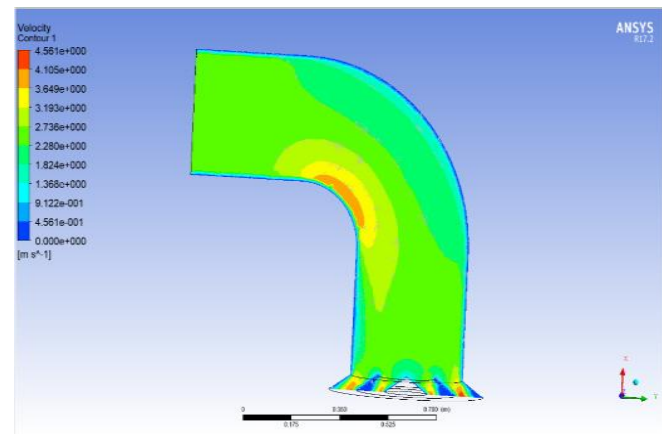

Fig. 23. Velocity contour C16

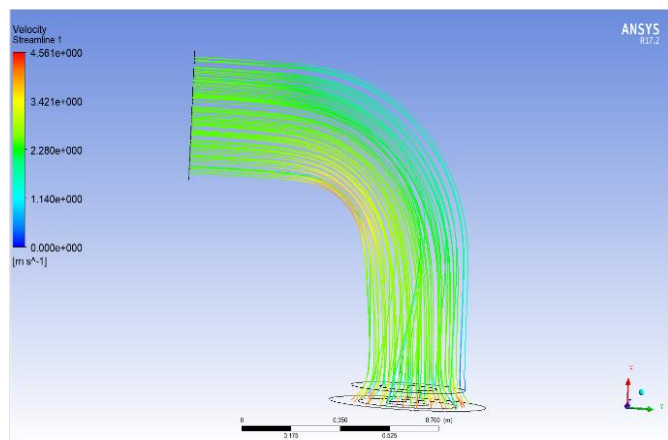

Fig. 24. Velocity streamline C16

\begin{tabular}{|c|c|c|c|}
\hline & CIRCLE & SQUARE & RECTANGLE \\
\hline $\begin{array}{c}\text { Max } \\
\text { Pressure[Pa] }\end{array}$ & 11.879 & 6.773 & 12.83 \\
\hline $\begin{array}{c}\text { Min } \\
\text { Pressure[Pa] }\end{array}$ & -6.038 & -6.545 & -9.16 \\
\hline $\begin{array}{c}\text { Inlet } \\
\text { Pressure[Pa] }\end{array}$ & 8.184 & 5.237 & 9.684 \\
\hline $\begin{array}{c}\text { Bend } \\
\text { Pressure[Pa] }\end{array}$ & 7.185 & 4.862 & 8.76 \\
\hline $\begin{array}{c}\text { Outlet } \\
\text { Pressure[Pa] }\end{array}$ & 5.545 & 3.051 & 6.012 \\
\hline $\begin{array}{c}\text { Inlet } \\
\text { Velocity[m/s] }\end{array}$ & 2.5 & 2.5 & 2.5 \\
\hline $\begin{array}{c}\text { Outlet } \\
\text { Velocity[m/s] }\end{array}$ & 3.69 & 2.9 & 3.84 \\
\hline $\begin{array}{c}\text { Pressure } \\
\text { Drop[Pa] }\end{array}$ & 2.642 & 2.186 & 3.672 \\
\hline \multicolumn{2}{|c|}{ Table $5:-$ Results on the basis of shape } \\
\hline
\end{tabular}

Table 5:- Results on the basis of shape 


\section{On the basis of bend radius}

- CFD results on iterations based on different bend radius ration show that $\mathrm{R} 0$ notices high turbulence which results in eddy current formation and separation of boundary layer.

Pressure range in R0 is noticed to be the largest because of highly undefined flow. It also has an uneven flow at the outlet which leads to further pressure loss and gain in velocity. Due to this, it has high dynamic losses at the end causing high noise.

$>$ Due to lack of curvature at the bend, r0.5 and r0 face similar issues. But, due to a little bend in the upper bend wall, turbulence, eddy formation and flow separation is comparatively lower. Therefore, pressure drop and noise recorded in $\mathrm{r} 0.5$ is lower than $\mathrm{r} 0$.

$>\mathrm{R} 1$ enjoys lower pressure losses, lower turbulence, and lower hindrance in the flow of path and hence, lower noises due to a gradual bending curve for flow.

$>$ As the curvature of bend increases, a better development of flow is noticed with smallest flow-devoid region downstream of bend. This reduces the pressure drop across the bend and provides an even pressure contour across the bend.

$>$ The velocity gain throughout the system is similar in $\mathrm{R} 0$, $\mathrm{R} 0.5, \mathrm{R} 1$ and $\mathrm{R} 2$.

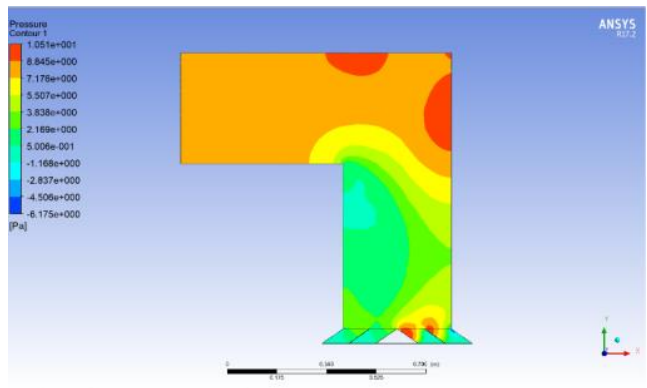

Fig. 25. Pressure contour R0

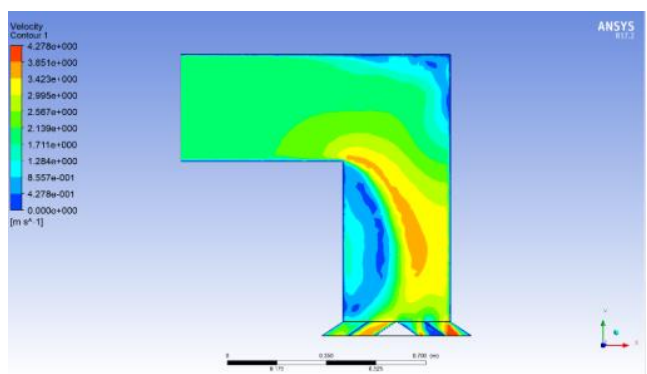

Fig. 26. Velocity contour R0

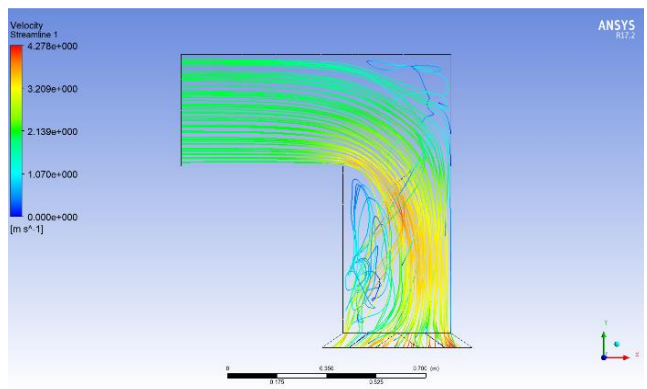

Fig. 27. Velocity streamline R0

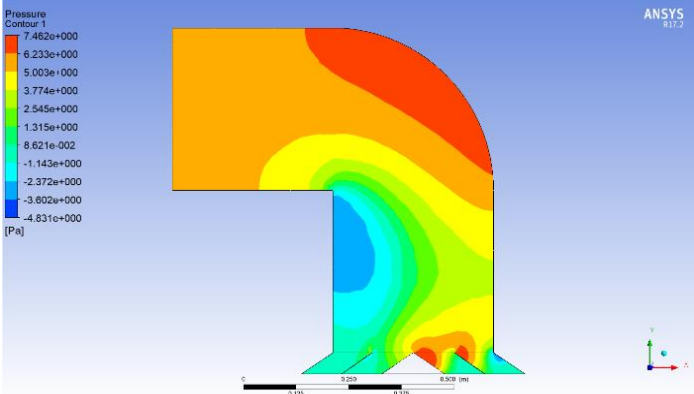

Fig. 28. Pressure contour R0.5

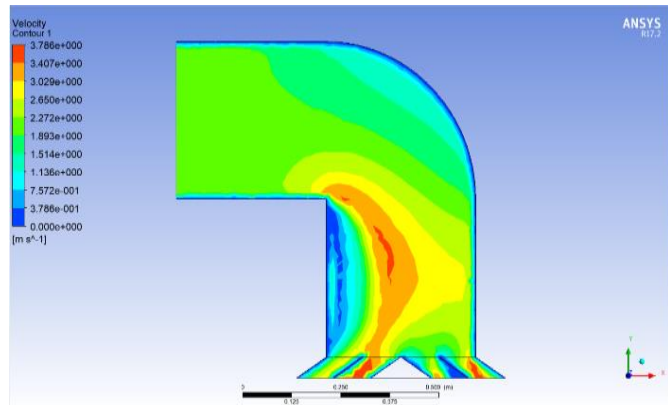

Fig. 29. Velocity contour R0.5

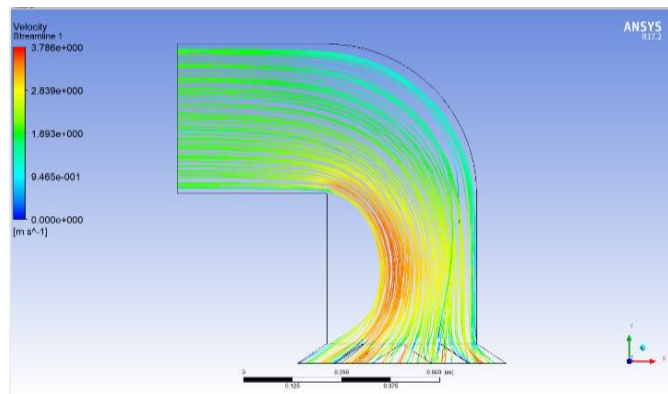

Fig. 30. Velocity streamline R0.5

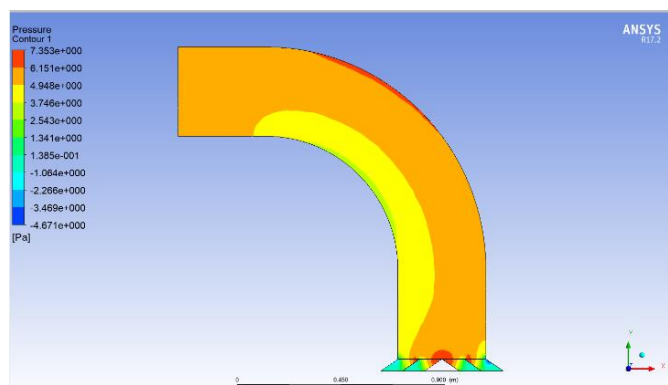

Fig. 31. Pressure contour R2

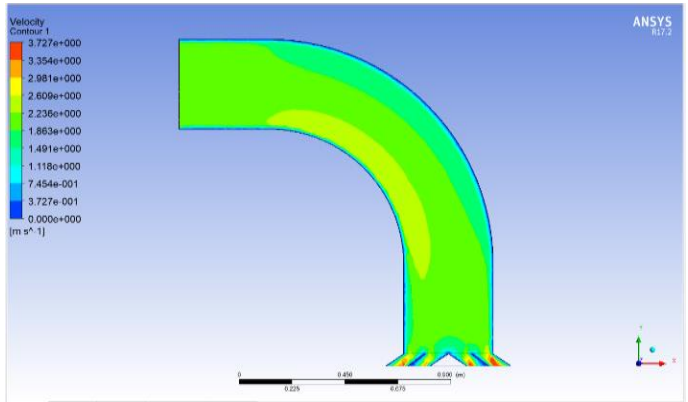

Fig. 32. Velocity contour R2 


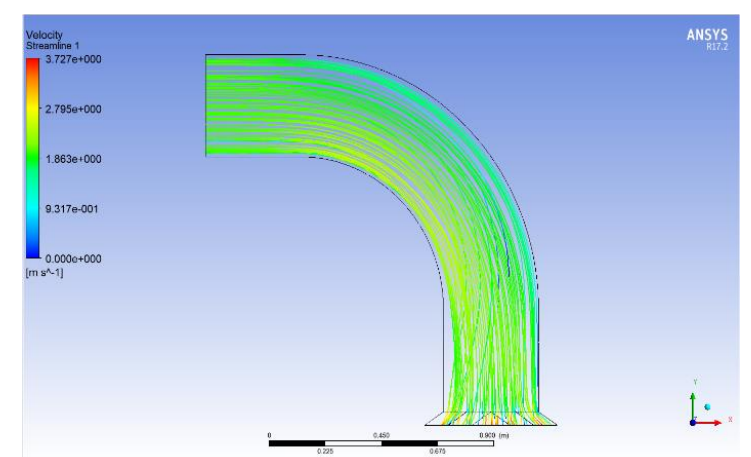

Fig. 33. Velocity streamline R2

\begin{tabular}{|c|c|c|c|c|}
\hline & $\mathbf{0}$ & $\mathbf{0 . 5}$ & $\mathbf{1}$ & $\mathbf{2}$ \\
\hline Max Pressure[Pa] & 10.51 & 7.462 & 6.773 & 7.35 \\
\hline Min Pressure[Pa] & -6.173 & -4.825 & -6.545 & -4.67 \\
\hline Inlet Pressure[Pa] & 8.192 & 5.502 & 5.237 & 5.409 \\
\hline Bend Pressure[Pa] & 6.541 & 4.455 & 4.862 & 5.037 \\
\hline Outlet Pressure[Pa] & 3.432 & 2.163 & 3.051 & 3.622 \\
\hline Inlet Velocity[m/s] & 2 & 2 & 2 & 2 \\
\hline Outlet Velocity[m/s] & 3.292 & 2.982 & 2.9 & 2.98 \\
\hline Pressure Drop[Pa] & 4.76 & 3.339 & 2.186 & 1.787 \\
\hline
\end{tabular}

Table 6:- Results on the basis of bend radius

\section{SUMMARY}

The CFD study and analysis performed on the basis of shapes showed that the pressure drop was least in case of circular followed by square and rectangle. But, due to difference in optimal operating speed varying from $2.5 \mathrm{~m} / \mathrm{s}$ in circular and rectangular to $2 \mathrm{~m} / \mathrm{s}$ in square shaped, difference in pressure drop is more of circular than square, but in case of percentage, drop percentage is least in case of circular hence, the circular type is the most efficient type compared to square and rectangular type in this order only.

> The CFD study and analysis performed on the basis of size of square diffusers with sides 12,15 and 18in shows trend in between them was observed to be similar with differences in output velocity, noise and throw. The noise was least in case of 18in square diffuser, but for optimum performance the noise criteria, output velocity, pressure drop and effective throw distance from the diffuser was noted in the 15 in $x 15$ in diffuser and duct system. Therefore, after studying the CFD, hence the 15 in $x 15$ in diffuser is the optimum design.

$>$ As r/W ratio increased from 0 to 2, CFD study showed that there was much lesser formation of eddy boundary layer separation and hence, lower levels of losses in pressure and due to friction. Therefore, for optimal design of system, r/W ratio of 2 is preferred as it will provide least turbulence along with less levels of disturbances due to vibrations and noise.

\section{CONCLUSION}

From the study, it was concluded that the circular ducts having a bend ratio of $r / W=2$, having three vanes in the bend having a diffusing angle of 33.7 degrees is most efficient keeping in mind the requirement of classroom to minimise the noise due to the system and also providing comfort cooling till the end of the room.

\section{REFERENCES}

[1]. A. Agarwal and L. Mthembu, "CFD analysis of conical diffuser under swirl flow inlet conditions using turbulence models," Materials Today, Volume 27, Part 2, 2020, Pages 1350-1355

[2]. Gayathri Sundaravadhanan, Heramba G Selvarajan and Bradley McPherson. "Classroom Listening Conditions in Indian Primary Schools: A Survey of Four Schools," Noise and Health, Vol. 19, Issue 86, 2017

[3]. Biswajit Goswami, Dr Yamin Hassan and Dr Arup JD Sarma, "The Effects of Noise on Students at School: A Review," International Journal of Latest Engineering and Management Research, Vol. 3, Issue 1,2018

[4]. S. F. Moujaes and S. Aekula, "CFD Predictions and Experimental Comparisons of Pressure

[5]. Saadeddin, Khaled Abdel Razzaq, "The Effects of Diffuser Exit Velocity and Distance Between Supply and Return Apertures on the Efficiency of an Air Distribution System in an Office Space,"Theses and Dissertations, 2016, Paper 1033

[6]. Ramazan, Jawaz Pasha and Abdul Mujeeb M, "CFD Simulation of Swirling Effect in S-Shaped Diffusing Duct by Swirl Angle of 10\%, IOSR Journal of Mechanical and Civil Engineering, Volume 6, Issue 2 (Mar. - Apr. 2013), PP 11-19

[7]. Mukesh Didwania, Lokesh Singh, Ashish Malik and Mangal S Sisodiya "Analysis of Turbulent Flow over a $90^{\circ}$ Bend of Duct Using In Centralized A. C. Plant by CFD Code," IOSR Journal of Mechanical and Civil Engineering, Volume 11, Issue 4 Ver. I (Jul- Aug. 2014), PP 41-48

[8]. ASHRAE Handbook Staff, "ASHRAE Handbook HVAC Systems and EquipmentIP," 2016

[9]. Central Public Works Department India, "Compendium of architectural norms and guidelines," 2019

[10]. Gulf Grilles Co., "Variable air volume", 2002

[11]. Gulf Grilles Co., "Ceiling Diffusers", 2007

[12]. Contact Privacy Inc., "Airflow calculations", < www.HVACtrainingsolutions.net>,2004 